\title{
Preliminary model of the thermographic image of the periodontum proposed on the basis of results for healthy subjects- preliminary study.
}

\author{
Dorota Burchardt*, Szczęsny Górski** \\ *Department of Paediatric Dentistry,K.Marcinkowski University \\ of Medical Sciences, \\ 60-806 Poznań, Rokietnicka 5D Street, Poland \\ phone/fax+48618687427,burchardt@go2.pl \\ ${ }^{* *}$ Radiophysical Laboratory, J.Struś Municipal Hospital ,61-833 \\ Poznań, \\ Szkolna 8/12 Street, \\ Poland, phone+48618522339, renoam@ewan.com.pl
}

Keywords: thermology, diagnostics, periodontology, gingiva, adolescents

Thermographic methods have been used in dentistry for diagnostics and for assessment of the effects of treatment of soft tissues (periodontum), for assessment of the effects of endodontic treatment, in implantology, for assessment of the effect of laser treatment on dental pulp and in assessment of reactivity of periodontum vessels in IDDM sufferers.

The aim of the study was to propose a thermographical model (reference standard) and compare the results of the clinical and thermographical assessment of the periodontal tissues in healthy adolescents.

The subjects were 18 healthy adolescents 16-17 years old, whose family members were also free from periodontal 
diseases, did not experience bleeding on teeth brushing and were in generally good health. The level of the oral cavity hygiene was described with the help of plaque index $\mathrm{PI}-\mathrm{I}$ after Silness \& Löe. The periodontal status was described with the help of GI after Silness \& Löe and SBI after Mühlemann \& Son. The thermographic study was performed using an AGA Thermovision System 680 in the basis of the thermographical analysis conditions.

The periodontal tissues in the thermographical analysis for the periodontum in the all subjects were free from periodonlal diseases $(\mathrm{SBI}=0,0)$.

The clinical and thermographical analysis was performed for the periodontum in the neighbourhood of the upper jaw incisors. The reactivity of the blood vessels was determined on cooling. The thermographic measurements were made prior to the cooling and a 1,2,3,and 4 minutes after cooling with cold water of a constant temperature $\left(1^{\circ} \mathrm{C}\right)$. The minimum, maximum and mean weighted temperatures were calculated separately for the left and right hand side of the periodontum.

The model values of the temperatures and the corresponding thermographic images obtained for these people can be used in further studies as reference standards. 
Fig.1. Thermographic image of periodontum in the vicinity of the upper jaw incisors in a healthy subject /no. 9/ recorded prior to cooling.

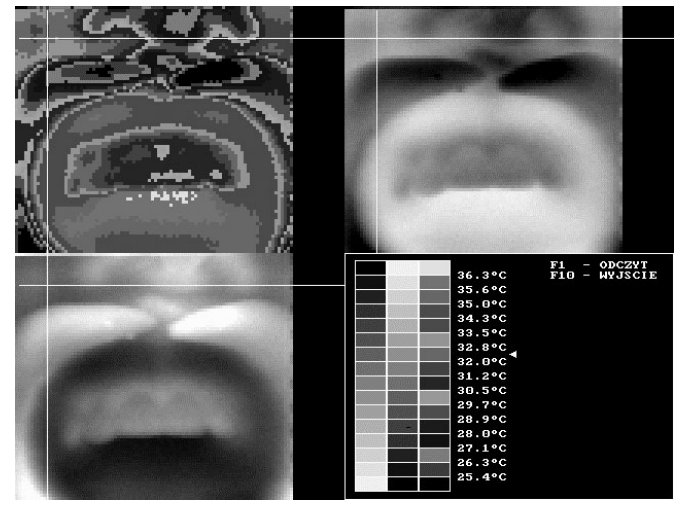

Fig.2. Thermographic image of periodontum in the vicinity of the upper jaw incisors in a healthy subject /no. 9/ recorded in 4 minutes after cooling.

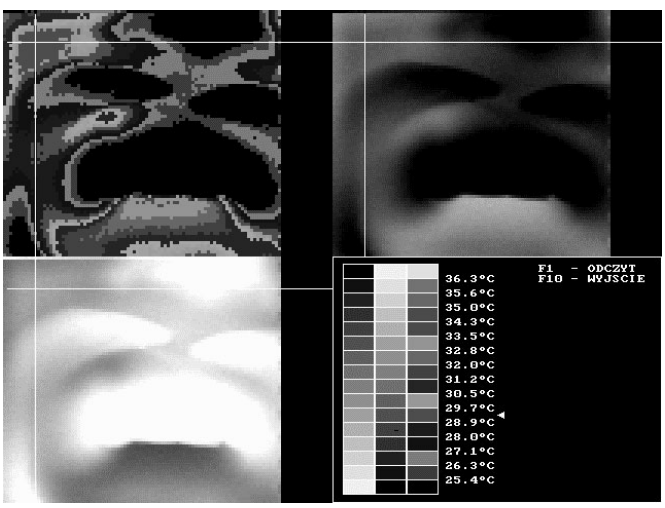


http://dx.doi.org/10.21611/qirt.2004.056 